\title{
Effect of HIP Treatment on Fatigue Crack Growth Behavior of Ti-6Al-4V Alloy Fabricated by Electron Beam Melting
}

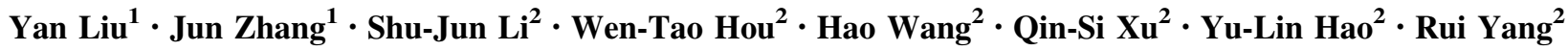

Received: 21 June 2017/Revised: 13 July 2017/Published online: 13 October 2017

(C) The Chinese Society for Metals and Springer-Verlag GmbH Germany 2017

\begin{abstract}
The effect of hot isostatic pressing treatment on the fatigue crack growth behavior of Ti-6Al-4V alloy fabricated by electron beam melting was investigated. The results indicate that the fatigue crack growth rate of the HIPed samples is higher than that of the as-fabricated one under certain stress intensity factor $\left(\Delta K<18 \mathrm{MPa} \mathrm{m}^{1 / 2}\right)$. With further increase in $\Delta K$, the fatigue crack growth rates of the studied two samples become similar. The variation of $\alpha$ lamella thickness and the pore defects distribution have an effect on the fatigue crack growth rates in the studied samples, and the latter plays the dominant role.
\end{abstract}

KEY WORDS: Electron beam melting; Ti-6Al-4V; Fatigue crack growth rate; $\alpha$ Lamella; Pores

\section{Introduction}

Electron beam melting (EBM) is a process of making additive material objects from the model of computer-aided designed parts by melting powder layers using an electron beam [1, 2]. This technique is being attracting more attention in biomedical fields due to their advantages of producing prototypes or finalized parts rapidly and costeffectively with providing accurate control over both internal architectures and complex shapes [3].

Ti-6Al- $4 \mathrm{~V}$ is a typical $\alpha+\beta$ dual-phase titanium alloy with excellent comprehensive mechanical properties and good biocompatibility. EBM-fabricated $\mathrm{Ti}-6 \mathrm{Al}-4 \mathrm{~V}$ has been investigated extensively till now $[4,5]$. Most of the

Available online at http://link.springer.com/journal/40195

Shu-Jun Li

shjli@imr.ac.cn

1 College of Mechanical Engineering, Shenyang University, Shenyang 110044, China

2 Shenyang National Laboratory for Materials Science, Institute of Metal Research, Chinese Academy of Sciences, Shenyang 110016, China investigations focused on the comprehensive understanding of the processing-microstructure-properties relationships. Variation of the build temperature was found to have a significant effect on the microstructure and properties of as-deposited Ti-6Al-4V alloys samples fabricated by EBM, while the mechanical properties are comparable to those of wrought materials $[2,6]$. Orientation has no influence on the ultimate strength (UTS) or yield strength (YS), whereas it has significant influence on elongation; however, part size has a significant influence on the UTS, YS, and elongation [7, 8].

During the service of the orthopedic implants, the excellent fatigue crack growth resistance can avoid the abrupt crack propagation in the implants. For their safe application in the human body, it is important to study the fatigue crack propagation properties of Ti-6Al-4V alloys fabricated by EBM. Concerning the effect of $\alpha^{\prime}$ martensites, previous studies have indicated that the fine $\alpha^{\prime}$ martensites make the main contribution to the prevention of fatigue crack propagation in $\mathrm{Ti}-6 \mathrm{Al}-4 \mathrm{~V}$ alloy by selective laser melting (SLM) [9]. However, the morphology of EBM Ti-6Al-4V alloy can be quite different from that of SLM alloy [10-14], and so their fatigue crack growth behavior may be different. Currently, there is a lack 
of relevant reports. Hence in the present work, the effect of HIP treatment on the fatigue crack propagation behavior of Ti- $6 \mathrm{Al}-4 \mathrm{~V}$ alloys fabricated by EBM was investigated and the dominant factors affecting the fatigue crack growth were elucidated.

\section{Experimental}

The Ti-6Al-4V powder for EBM process was provided by Arcam AB (Sweden). The chemical compositions obtained by wet chemical and gas analyses for $\mathrm{Ti}-6 \mathrm{Al}-4 \mathrm{~V}$ powder are shown in Table 1.

Samples with a dimension of $10 \mathrm{~mm} \times 10 \mathrm{~mm} \times$ $60 \mathrm{~mm}$ were fabricated by adjusting the EBM processing parameters. The building direction of the samples was perpendicular to the start plate. The distance between the adjacent samples was at least $20 \mathrm{~mm}$ to ensure heat dissipation of the samples in the process. Some of the EBM samples were HIP-treated on a QIH-15 hot isostatic pressing furnace at a temperature of $930{ }^{\circ} \mathrm{C}$ with a pressure of $130 \mathrm{MPa}$ for $3 \mathrm{~h}(18 \mathrm{ks})$, and then the furnace was cooled down to room temperature. In order to discern the dominant factor governing the fatigue crack growth, some of the samples were heat treated at $930{ }^{\circ} \mathrm{C}$ for $3 \mathrm{~h}$, and then the furnace is cooled down to room temperature. Tensile tests were carried out at tensile rate of $2.5 \times 10^{-4} / \mathrm{s}$ using an Instron 8872 machine. The fatigue crack growth experiments at stress ratios $R$ of 0.1 and a frequency of $10 \mathrm{~Hz}$ were performed by using an Instron E10000 machine according to GBT 6398-2000, and the geometries of fatigue crack growth samples were shown in Fig. 1. The fatigue loading of the specimens consisted of axial tension in a sinusoidal waveform in air at room temperature. Microstructural analyses were performed using a ZEISSAXIO optical microscope (OM) and an S-3400 N scanning electron microscope (SEM). The studied samples for OM analysis were mechanically polished and then etched in a solution consisting of $20 \% \mathrm{HF}, 50 \% \mathrm{HNO}_{3}$, and $30 \% \mathrm{H}_{2} \mathrm{O}$. The fracture surfaces of the samples were observed by SEM. Before observation, the fracture surfaces of the samples were cleaned by alcohol. The samples were carried out by Micro-CT scan analysis at an accelerating voltage of $160 \mathrm{kV}$ and current of $62.5 \mu \mathrm{A}$ using a Zeiss Versa 500 Micro-CT system in order to find the pores in EBM samples. The Micro-CT 3D data were analyzed by Avizo 8.0 software.

\section{Results}

\subsection{Microstructure}

As shown in Fig. 2, the EBM Ti-6Al-4V samples mainly consist of $\alpha$ phase. There are intergranular $\beta$ grains with a small volume fraction between adjacent $\alpha$ grains, resulting from fast cooling solidification of the samples from the $\beta$ phase transformation temperature [15]. The thickness of the $\alpha$ lamellae measured by the broken line method is $\sim 1.3 \mu \mathrm{m}$ and $\sim 2.5 \mu \mathrm{m}$ for the as-fabricated and HIPtreated samples, respectively.

\subsection{Defect Analysis}

Figure 3 indicates that the pores are the main defects in asfabricated EBM samples. Most of the pores in the EBM samples are spherical with a size about $39 \mu \mathrm{m}$. The formation of these pores is mostly due to two reasons. Firstly, during the preparation of $\mathrm{Ti}-6 \mathrm{Al}-4 \mathrm{~V}$ powders with the gas atomization method [16], residual argon gas inevitably attaches to the powder surface, which may lead to the formation of the pores during melting [6]. Secondly, the powders can easily produce a large amount of metal vapor due to the gasification by high energy density electron beam. Some of the metal vapor cannot be discharged in time during the movement of the molten pool, which results in the formation of pore defects [17]. Pores in asfabricated Ti-6Al-4V samples can be significantly eliminated by HIP treatment (Fig. 3b) [18].

\subsection{Tensile Property}

The tensile properties of the as-fabricated and HIPed samples are listed in Table 2. Compared with the HIPed samples, the as-fabricated sample possesses higher tensile strength (YS: $955 \mathrm{MPa}$; UTS: $1036 \mathrm{MPa}$ ), whereas the lower ductility [19]. According to the results shown in Fig. 2, the different mechanical properties of the studied alloys are relevant to the thickness of $\alpha$ lamellae. For dualphase titanium alloys, it is well known that the relation

Table 1 Chemical compositions of Ti-6Al-4V alloy powders used in this study (in wt\%)

\begin{tabular}{lllllllrrr}
\hline & Al & V & Ti & Fe & C & N & H & O \\
\hline GB/T3620.1-1994 & $5.5-6.8$ & $3.5-4.5$ & Balance & 0.3 & 0.1 & 0.05 & 0.015 \\
EBM powder & 6.04 & 4.05 & Balance & 0.07 & 0.013 & $<0.005$ & $<0.005$ & 0.13 \\
\hline
\end{tabular}



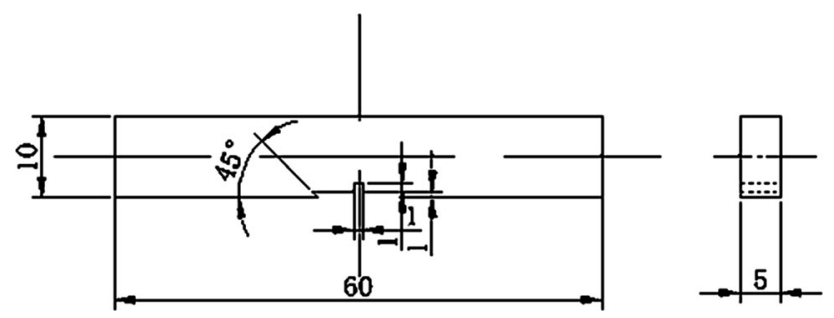

Fig. 1 Geometries of fatigue crack growth samples for EBM Ti$6 \mathrm{Al}-4 \mathrm{~V}$ alloy in this investigation

between strength and $\alpha$ thickness follows the Hall-Petch relationship [20, 21]:

$\sigma_{\mathrm{ys}}=\sigma_{0}+K_{\mathrm{y}} d^{-1 / 2}$

where $\sigma_{0}$ is the single crystal yield strength, $K_{\mathrm{y}}$ the strengthening coefficient, and $d$ the thickness of lamellae. Therefore, it is expected that the observed increase in the $\alpha$ lamellae thickness in HIPed samples (Fig. 2b) will cause a decrease in strength.

\subsection{Fatigue Crack Growth Behavior}

The fatigue crack growth curves of the as-fabricated and HIPed samples are shown in Fig. 4. It is noted that when the stress intensity factor $(\Delta K)$ is lower than $18 \mathrm{MPa} \mathrm{m}^{1 / 2}$, the fatigue crack growth rate of the HIPed samples is higher than that of the as-fabricated samples. With the increase of the stress intensity, the fatigue crack growth rates of both samples show similar tendency.

The fatigue crack propagation paths of the as-fabricated and HIPed samples are shown in Fig. 5. There are two main types of fatigue crack growth manners. One is propagation along the $\alpha / \beta$ interface (Fig. 5). Because of the stronger binding between $\alpha$ lamellae than $\alpha / \beta$ interfaces, the $\alpha / \beta$ interface becomes the weak path for crack propagation [22]. The other is propagation in a certain angle with respect to the lamella interface, as determined by the structure at the crack tip and the angle between the directions of stress and lamellar (Fig. 5). It is interesting that large number of secondary cracks were observed around

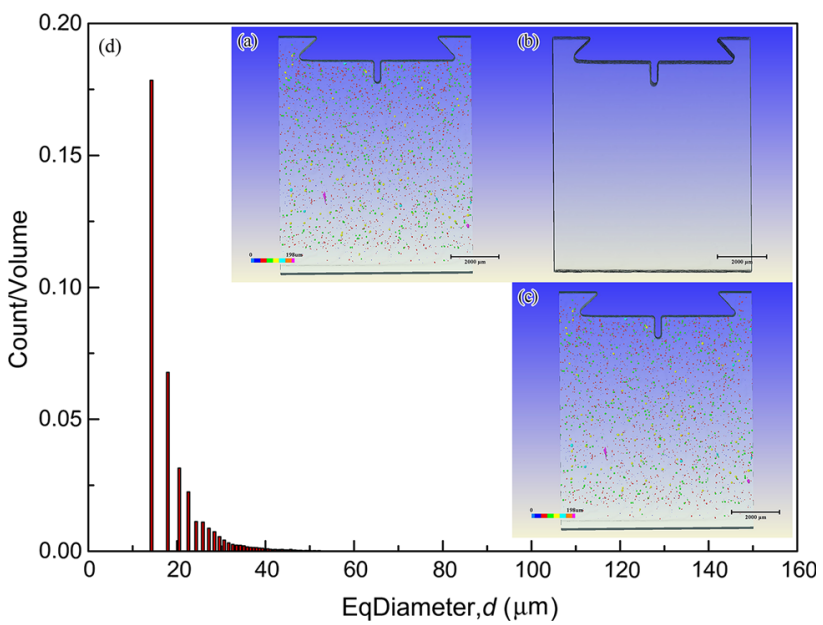

Fig. 3 Micro-CT results of as-fabricated $a$, HIPed $b$, heat-treated $c$ samples, and pore distribution $d$ of the as-fabricated sample

Table 2 Tensile properties of the studied EBM Ti-6Al-4V samples

\begin{tabular}{lrlll}
\hline Conditions & \multicolumn{1}{l}{$\begin{array}{l}\text { UTS } \\
(\mathrm{MPa})\end{array}$} & $\begin{array}{l}\text { YS } \\
(\mathrm{MPa})\end{array}$ & EL (\%) & RA (\%) \\
\hline As-fabricated & $1036 \pm 5$ & $955 \pm 3$ & $14.7 \pm 0.6$ & $42.6 \pm 0.2$ \\
EBM + HIP & $979 \pm 2$ & $887 \pm 5$ & $16.7 \pm 0.5$ & $51.7 \pm 0.1$ \\
$\begin{array}{l}\text { EBM + Heat } \\
\text { treatment }\end{array}$ & $930 \pm 4$ & $866 \pm 7$ & $18.2 \pm 0.3$ & $75.3 \pm 0.1$ \\
\hline
\end{tabular}

the pores in the as-fabricated samples (Fig. 6a). However, in the HIPed samples, only straight main cracks were observed.

\section{Discussion}

Fatigue crack growth behavior in titanium alloys was investigated extensively. For $\alpha+\beta$ titanium alloys, the crystallographic orientation of $\alpha$ laths, $\alpha / \beta$ boundary, and plastic deformation zone at the fatigue crack tip have been considered as the main factors influencing crack growth behavior [23-28]. In the present investigation, the studied EBM samples of the as-fabricated and HIPed show
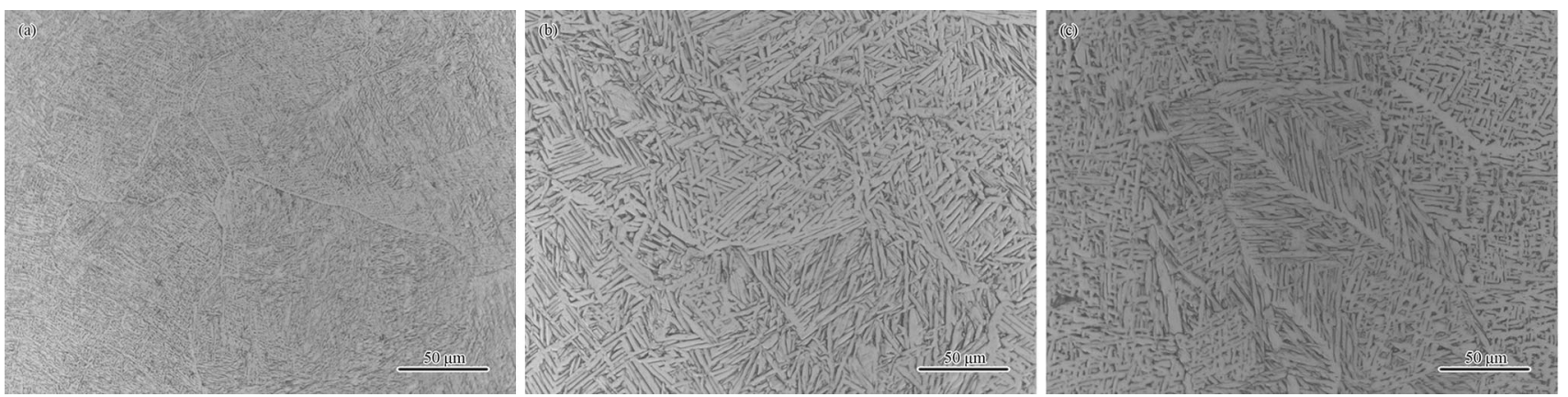

Fig. 2 Optional microstructures of as-fabricated a, HIPed b heat treated $\mathbf{c}$ Ti-6Al-4V samples 


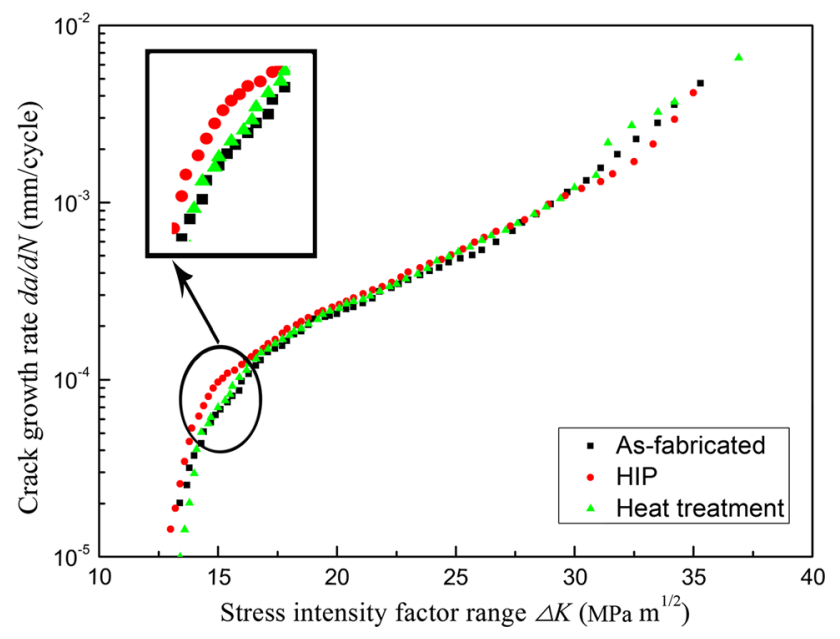

Fig. 4 Fatigue crack growth curves of the studied EBM Ti-6Al-4V samples

different morphologies, defects, and mechanical properties. Based on the experimental results, the different fatigue crack propagation behaviors of the as-fabricated and HIPed samples in the range of $\Delta K<18 \mathrm{MPa} \mathrm{m}^{1 / 2}$ were discussed, and the underlying mechanism was elucidated.

\subsection{Plastic Zone Ahead of the Fatigue Crack Tip}

The plastic zone ahead of the fatigue crack tip plays an important role in the fatigue crack growth in metallic materials $[29,30]$. The expansion of the crack tip plastic zone (CTPZ) can promote crack closure, which decreases the length of the effective crack and accordingly the fatigue crack growth rate [31]. The plastic zone size ahead of a fatigue crack tip can be determined by Eq. (2) [32]:

$r_{\mathrm{p}}=\frac{1}{3} \pi\left(\frac{K_{\max }}{\sigma_{\mathrm{y}}}\right)^{2}$

where $r_{\mathrm{p}}$ is the plastic zone size ahead of the crack tip, $K_{\max }$ is the maximum stress intensity factor, and $\sigma_{\mathrm{y}}$ is the yield strength. With the data in Table 2, the CTPZ sizes in the studied two kinds of the samples were calculated by Eq. (2) as 32 and $37 \mu \mathrm{m}$, respectively. The previous studies have indicated that crack growth rate is decreased with the increase of the CTPZ size. However, the present results show an opposite tendency. Thus, it seems that variation of plastic zone ahead of the crack is not the dominant factor influencing the fatigue crack growth of the studied EBM samples.
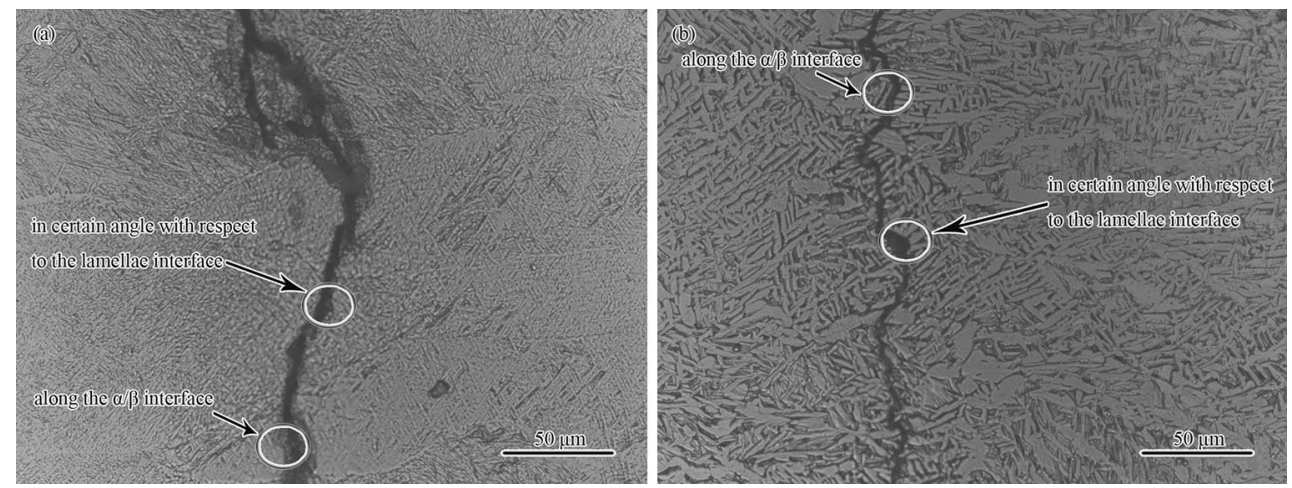

Fig. 5 Fatigue crack propagation paths of as-fabricated a HIPed b samples
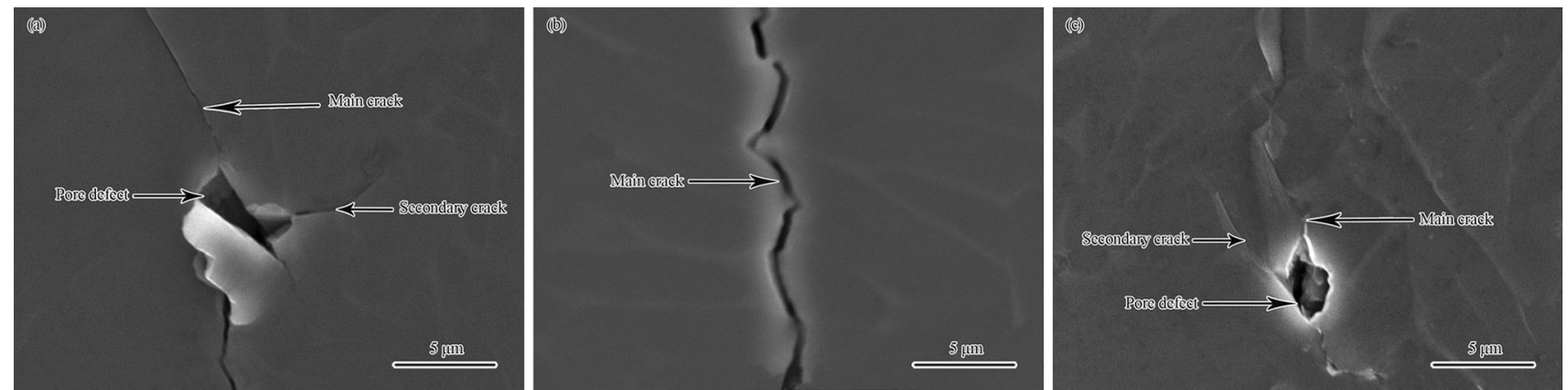

Fig. 6 SEM images of the fracture surfaces of the as-fabricated a, HIPed $\mathbf{b}$ heat-treated $\mathbf{c}$ samples 


\subsection{Morphology of $\alpha$ Lamella}

Due to the relative high heat-treatment temperature $\left(930{ }^{\circ} \mathrm{C}\right)$, i.e., close to $\beta$ transus temperature $\left(980 \pm 10^{\circ} \mathrm{C}\right.$ ), and the subsequent slow cooling (furnace cooling), the $\alpha$ phase regions are much coarser and the colonies are larger in HIPed samples compared with the asfabricated ones. The variation of the morphology of $\alpha$ phase may contribute to the higher fatigue crack growth in the HIPed sample. Firstly, it is reported that the crack comes across fewer mounts of $\alpha$ lamella at a certain distance with the increase of the $\alpha$ lamella thickness [33]. Thus, the coarser $\alpha$ lamella may lead to the increase of the fatigue crack growth rate. Secondly, as the size of the colonies increases, the effective fatigue crack propagation lengths increases and the deflective degree of the propagation path decreases. Thus, the energy required for crack propagation is reduced, and the crack propagation rate is accelerated [22].

\subsection{Pore Defects}

Under the condition of definite load and loading direction, the pre-crack propagated along the main crack direction in the experiment. In this study, when the crack passes through the pore defect, secondary cracks appear near the primary crack (Fig. 6a). The secondary cracks can reduce the energy needed for the primary crack and then retard fatigue crack propagation. After HIP treatment, most of the pores are eliminated (Fig. 3b) [10], and the fatigue crack only propagates along the pre-crack-tip direction (Fig. 6b), resulting in higher fatigue crack growth rate in HIPed samples.

The above analysis indicates that both the $\alpha$ phase morphologies and the defects in the as-fabricated and HIPed samples may affect the different fatigue crack growth behaviors. In order to elucidate the dominant factors, the fatigue crack growth behavior of the EBM samples with the similar thermal process to HIPed samples was investigated. The results indicate that although the heattreated sample has similar $\alpha$ morphology $(\sim 2.5 \mu \mathrm{m})$ (Fig. 2c) and mechanical properties (YS: $866 \mathrm{MPa}$; UTS: $930 \mathrm{MPa}$ ) with HIPed sample (Table 2), the fatigue crack growth rate is lower. The result indicates that in the two factors, defects may contribute to more for decreasing the fatigue crack growth. For EBM product, pore defects are inevitable during fabrication. These pores can accelerate the fatigue crack initiation in EBM product $[10,34]$. Since the high cycle fatigue life of metallic materials is mainly determined by the fatigue crack initiation life during cyclic deformation, these pores are detrimental to the high cycle fatigue properties [10]. The result presented in this work indicates that these pores may deflect the fatigue crack and retard the fatigue crack propagation.

\section{Conclusions}

In this study, the effect of HIP treatment on the fatigue crack growth of EBM Ti-6Al-4V sample was investigated and the following conclusions are drawn:

1. In the stage of $\Delta K<18 \mathrm{MPa} \mathrm{m}^{1 / 2}$, the fatigue crack growth rate of the HIPed samples is higher than that of the as-fabricated one. With further increase in $\Delta K$, the fatigue crack growth rates of the two studied samples become similar.

2. The variation of $\alpha$ lamella thickness and the pore defect distribution can affect the fatigue crack growth rates in Ti-6Al-4V alloys fabricated by EBM, but the latter plays the dominate role in the fatigue crack growth.

Acknowledgements This work was supported partially by MoST project (2017YFC1104900, 2016YFC1102601), National Natural Science Foundation of China $(51271182,51631007)$.

\section{References}

[1] H. Galarraga, R.J. Warren, D.A. Lados, R.R. Dehoff, M.M. Kirka, P. Nandwana, Mater. Sci. Eng. A 685, 417 (2017)

[2] L.E. Murr, S.A. Quinones, S.M. Gaytan, M.I. Lopez, A. Rodela, E.Y. Martinez, D.H. Hernandez, E. Martinez, F. Medina, R.B. Wicker, J. Mech. Behav. Biomed. Mater. 2, 20 (2009)

[3] Y.J. Liu, S.J. Li, W.T. Hou, S.G. Wang, Y.L. Hao, R. Yang, T. Sercombe, L.C. Zhang, J. Mater. Sci. Technol. 32, 505 (2016)

[4] Y.J. Liu, H.L. Wang, S.J. Li, S.G. Wang, W.J. Wang, W.T. Hou, Y.L. Hao, R. Yang, L.C. Zhang, Acta Mater. 126, 58 (2017)

[5] Y.J. Liu, S.J. Li, H.L. Wang, W.T. Hou, Y.L. Hao, R. Yang, T.B. Sercombe, L.C. Zhang, Acta Mater. 113, 56 (2016)

[6] S.S. Al-Bermani, M.L. Blackmore, W. Zhang, I. Todd, Metall. Mater. Trans. A 41, 3422 (2010)

[7] N. Hrabe, T. Quinn, Mater. Sci. Eng. A 573, 271 (2013)

[8] Z. Wang, J. Zhang, S.J. Li, W.T. Hou, Y.L. Hao, R. Yang, Rare Metal Mater. Eng. 43, 161 (2014). (in Chinese)

[9] B.V. Hooreweder, D. Moens, R. Boonen, J.P. Kruth, P. Sas, Adv. Eng. Mater. 14, 92 (2012)

[10] X.L. Zhao, S.J. Li, M. Zhang, Y.D. Liu, T.B. Sercombe, S.G. Wang, Y.L. Hao, R. Yang, L.E. Murr, Mater. Des. 95, 21 (2016)

[11] Y. Bai, X. Gai, S.J. Li, L.C. Zhang, Y.J. Liu, Y.L. Hao, X. Zhang, R. Yang, Y.B. Gao, Corros. Sci. 123, 289 (2017)

[12] N.W. Dai, L.C. Zhang, J.X. Zhang, Q.M. Chen, M.L. Wu, Corros. Sci. 102, 484 (2016)

[13] N.W. Dai, L.C. Zhang, J.X. Zhang, X. Zhang, Q.Z. Ni, Y. Chen, M.L. Wu, C. Yang, Corros. Sci. 111, 703 (2016)

[14] N.W. Dai, J.X. Zhang, Y. Chen, L.C. Zhang, J. Electrochem. Soc. 164, C428 (2017)

[15] L.E. Murr, S.M. Gaytan, D.A. Ramirez, E.Y. Martinez, J. Hernandez, K.N. Amato, P.W. Shinndo, F.R. Medina, R.B. Wicker, J. Mater. Sci. Technol. 28, 1 (2012) 
[16] R.P. Guo, L. Xu, Y.P. Zong, R. Yang, Acta Metall. Sin. (Engl. Lett.) 30, 735 (2017)

[17] H.B. Suo, Z.Y. Chen, J.W. Li, Aerosp. Manuf. Technol. 12, 18 (2009)

[18] A. Safdar, L.Y. Wei, A. Snis, Z. Lai, Mater. Charact. 65, 8 (2012)

[19] S.L. Lu, H.P. Tang, Y.P. Ning, N. Liu, D.H. Stjohn, M. Qian, Metall. Mater. Trans. A 46, 3824 (2015)

[20] L.E. Murr, E.V. Esquivel, S.A. Quinones, S.M. Gaytan, M.I. Lopez, E.Y. Martinez, F. Medina, D.H. Hernandez, E. Martinez, J.L. Martinez, S.W. Stafford, D.K. Brown, T. Hoppe, W. Meyers, U. Lindhe, R.B. Wicker, Mater. Charact. 60, 96 (2009)

[21] Z. Zhao, J. Chen, S. Guo, H. Tan, X. Lin, W.D. Huang, J. Mater. Sci. Technol. 33, 675 (2017)

[22] X. Feng, S. Peng, Y.J. Ma, J.F. Lei, X.H. Wu, Y.Y. Cui, R. Yang, Chin. J. Nonferrous Met. 23, s462 (2013)

[23] S.R. Dey, A. Hazotte, E. Bouzy, S. Naka, Acta Mater. 53, 3783 (2005)
[24] K.S. Ravichandran, Acta Metall. Mater. 39, 401 (1991)

[25] K.S. Chan, C.C. Wojcik, D.A. Koss, Metall. Mater. Trans. A 12, 1899 (1981)

[26] M.R. Bach, W.J. Evans, V. Randle, R.J. Wilson, Mater. Sci. Eng. A 257, 139 (1998)

[27] Y. Takahashi, M. Tanaka, K. Higashida, K. Yamaguchi, H. Nonguchi, Acta Mater. 58, 1972 (2010)

[28] K. Prasad, S.V. Kamat, J. Alloys Compd. 491, 237 (2010)

[29] M. Toyosada, K. Gotoh, Int. J. Fatigue 26, 983 (2004)

[30] Y. Xiong, X.X. Hu, Int. J. Fatigue 30, 67 (2008)

[31] J. Pokluda, R. Pippan, Mater. Sci. Eng. A 462, 355 (2007)

[32] Y.J. Ma, J.R. Liu, J.F. Lei, Y.Y. Liu, R. Yang, Chin. J. Nonferrous Met. 10, 1789 (2009)

[33] Y.J. Ma, J.W. Li, J.F. Lei, Z.Y. Tang, Y.Y. Liu, R. Yang, Acta Metall. Sin. 46, 1086 (2010). (in Chinese)

[34] H.P. Tang, J. Wang, C.N. Song, N. Liu, L. Jia, J. Elambasseril, M. Qian, JOM 69, 466 (2017) 